\title{
EXPERIMENTAL STUDY OF THE DYNAMIC FIELD OF TURBULENT PREMIXED METHANE/AIR FLAME USING PIV TECHNIQUE
}

\author{
M.S. BOULAHLIB, M. CHEKIRED, M. BENZITOUNI \& S. BOUKEBBAB \\ LITE, University Mentouri Constantine, Algeria.
}

\begin{abstract}
This work is an experimental study of the dynamic fields of a turbulent premixed methane-air flame in a Bunsen burner. The Particle Image Velocimetry (PIV) is used to determine the dynamic fields, and Laser Sheet Tomography (LST) for the flame fronts. The turbulent main jet has a Reynolds number $\mathrm{Re}=10000$. Turbulence is generated using perforated grids having three whose provide different inlet turbulence intensities. Velocity fields are measured for various equivalence ratio $(\Phi=0.6-1.3)$ and different axial flame positions. For the reactive jet, interesting results are obtained concerning the dynamic field and the flame front. It is shown that radial profiles of $\mathrm{U}$ and $\mathrm{V}$ correspond to the axial positions located before the end of the potential core in the reactive jet. The velocity increases at the jet center to $20 \mathrm{~m} / \mathrm{s}$, and is less influenced by turbulent mixing in the flame. The greatest velocity and turbulent kinetic energy are obtained using the grid with the smallest ratio (d/M). Most important values of the radial velocity correspond to the lean flames.

Keywords: dynamic field, grid turbulence, premixed combustion.
\end{abstract}

\section{INTRODUCTION}

The various technological applications of premixed turbulent combustion require a better understanding of the flow structure, the mechanisms of the flame stabilization and also their extinction limits. The improvement of each element needs well characterization of the morphology of the inner flow and other phenomena relating to the temperature distribution in the flame, interaction between turbulence and chemical reactions, dynamic behavior and flame stability [1]. For many years, different aspects of this combustion were studied [2-5]. Bray et al. [6] have assumed that the density variations could overcome the viscous dissipation and lead due to thermal expansion to a net production of turbulent kinetic energy in the flame. In their work on gas dynamics in flames, Plessing et al. [7] have shown that the turbulence intensity is decreased at the downstream by the flame but remains substantially constant at the burner exit. A comparison between the cold and reactive dynamic fields was presented by Deschamps [8], and an increase in the axial velocity due to the acceleration of the particles on the flame front has been highlighted. A significant increase in the turbulence intensity between the cold and reactive flow cases was observed. The role of the laminar flame thickness was recognized as an important parameter for study and comprehension of the flame/turbulence interactions [9]. Various studies have tried to analyze the influence of chemical reaction due to combustion on turbulence field flame [3, 4, 10-14]. Chekired et al. [15] using Peters and Williams mechanism, showed good agreement between the numerical results and the experimental ones of the Aachen flame F3. Battista et al. numerically and experimentally studied turbulent premixed flames in different flame regimes. The fractal scaling properties of turbulent premixed flame fronts have been investigated taken into consideration for the LES and DNS modeling [16]. Tamadonfar \& Gülder have experimentally studied the influence of the equivalence ratio, turbulence intensity and Bunsen burner diameter on the aerodynamic characteristics, the flame brush characteristics, instantaneous flame front structures, and burning velocities in the context of lean, stoichiometric and rich turbulent 
premixed flames. The Particle Image Velocimetry (PIV) and Rayleigh scattering techniques were used to measure the dynamic fields, temperature fields, and turbulence statistics. Perforated plates were used to generate different turbulence levels. Results show that the height flame is very sensitive to the equivalence ratio and burner diameter. The non-dimensional leading edge turbulent burning velocity improved with non-dimensional turbulence intensity for the different burners used. The effect of the equivalence ratio and turbulence intensity on the mean turbulent flame stretch factor has been studied. The flame brush thickness improved with increasing axial distance from the burner exit and equivalence ratio [17-19]. Leventiu et al. experimentally and numerically studied the instantaneous thermal structure of the flame front of premixed turbulent combustion of the lean methane-air mixture. A decreasing of averaged temperature gradient was observed for turbulent combustion case. The results show that the flame front thickness PDF and the curvature PDF decrease with the turbulence intensity [20]. More recently, a work using Mie scattering on lean premixed methane Bunsen flames has investigated the interactions between turbulence and the flame front. The results show that the smallest scales reduce the total flame brush. For different mode, the flame front length is carried out [21].

This work constitutes a parametric study of conical premixed turbulent flames for various conditions of equivalence ratio and turbulence to observe their impact on the local dynamic field structure. It is essential to understand how the velocity and equivalence ratio, locally influence the flame propagation in turbulent environments. The PIV is used to determine the dynamic fields in a turbulent premixed methane/air flame. The flame front was identified using Laser Sheet Tomography (LST). The characterization of the aerodynamic field in the turbulent flames is achieved using a reactive air-methane mixture with different equivalence ratio conditions $(\Phi=0.6 \div 1.3)$. The LST will provide information on front positions. Besides determining the velocity profiles, this study also aims to analyze the different characteristics and parameters influencing combustion along with a better understanding of local interaction mechanisms between turbulence structure and flame dynamics. The combustion is produced in flamelet regime. The results presented can be used like a data base for numerical model validation.

\section{EXPERIMENTAL SET-UP}

Optical systems with powerful laser light sources and light detectors have the disturbing less advantage the studied system, to obtain averages and instantaneous flame properties with a spatial resolution generally very satisfactory. The PIV System was used to determine the aerodynamic characteristics of both reactive and non-reactive flows. A self-calibration eliminates calibration errors. A laser sheet illuminates the flow at two successive instants [22]. A camera collects images of the two illuminated particle field. Thus, the particles present on the images are being moved between the two times of recording. Digital processing of the obtained images allows finding the velocity field at given instant [23, 24]. A Computer processing of the PIV image determines the median vector field ( $\mathrm{U}$ and V) from the vectors window and deviation of neighboring vectors ( $u^{\prime}$ and v'). The experiments are carried out on a Bunsen burner. The main jet in the burner is issuing from a $30 \mathrm{~mm}$ diameter and consisting of methane/air mixture surrounded by a pilot flame and coflow. The turbulent main jet has a Reynolds number $(\mathrm{Re}=10000)$ based on the burner nozzle diameter. The turbulence level at the inlet is generated by an interchangeable grid set ( 03 grids: $P, M$ and $G$ ), with ' $d$ ' is the hole diameter, ' $M$ ' is the mesh, $\sigma$ is the solidity and $C_{D}$ is the pressure drop coefficient (Table 1). A seeding zirconium oxide particles were used (Fig. 2). Equivalence ratio is controlled by varying the air flow and methane using sonic throat appropriately calibrated, while maintain- 


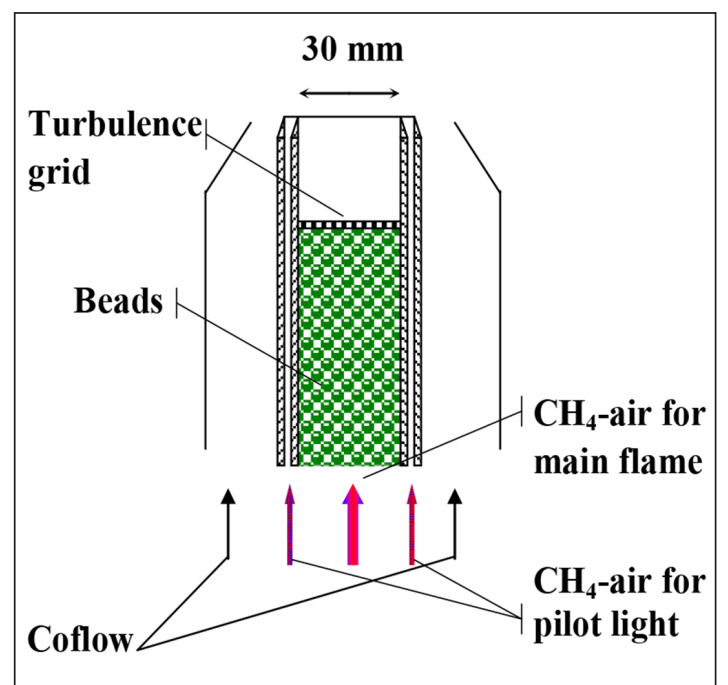

Figure1: Burner.

Table 1: Grids geometric characteristics.

\begin{tabular}{lcccccc}
\hline Grid & $\mathbf{M}(\mathbf{m m})$ & $\mathbf{d}(\mathbf{m m})$ & $\mathbf{d} / \mathbf{M}$ & $\sigma(\%)$ & $\mathbf{C}_{\mathbf{D}}(\boldsymbol{\%})$ & $\mathbf{u}^{\prime} / \mathbf{U}(\boldsymbol{\%})$ \\
\hline $\mathrm{P}$ & 2.40 & 2 & 0.83 & 0.38 & 37.5 & 7.5 \\
$\mathrm{M}$ & 3.52 & 3 & 0.85 & 0.34 & 26.5 & 13.4 \\
$\mathrm{G}$ & 4.54 & 4 & 0.88 & 0.30 & 18.4 & 12.4 \\
\hline
\end{tabular}

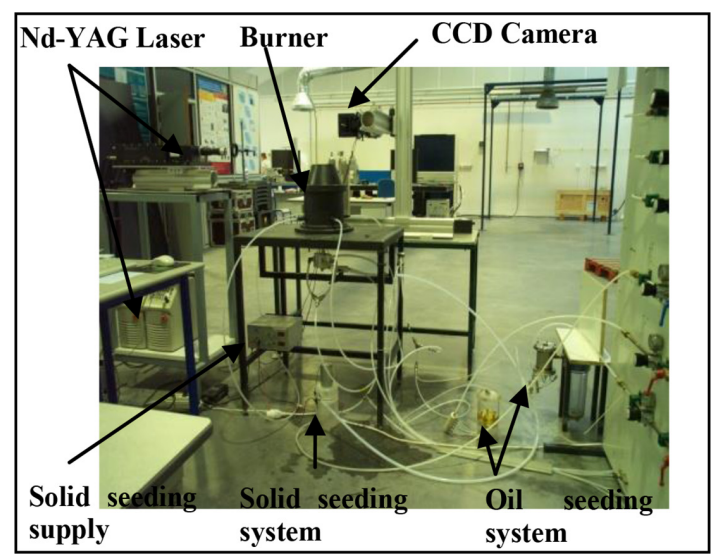

Figure 2: Experimental set up. 
ing the flow outlet constant. In our range, the flames can be classified into three categories: stoichiometric having a $\Phi$ equal or close to 1 ; fuel rich between 1.1 and 1.3 and fuel lean between 0.9 and 0.6 [25].

\section{RESULTS}

The study of local aerodynamics in the reaction zone is necessary to understand the interaction phenomena between the flame and turbulence for turbulent premixed flame.

3.1 V and U velocities and their fluctuations v' and u' (rms)

Figures 3 and 4 represent the radial and axial velocities component in the reactant field. From Figs 3 and 4, radial profiles of $U$ and $V$ correspond to the axial positions located before the end of the potential core of the reactive jet. The velocity increases at the jet center to $20 \mathrm{~m} / \mathrm{s}$. Further stream a decrease in flow velocity is observed due to the jet expansion and dissipation mechanisms. It's a change in the gradient evolution in the flame location area in the axial directions. This is largely due to the heat release. We can observe also a gradient decrease, a

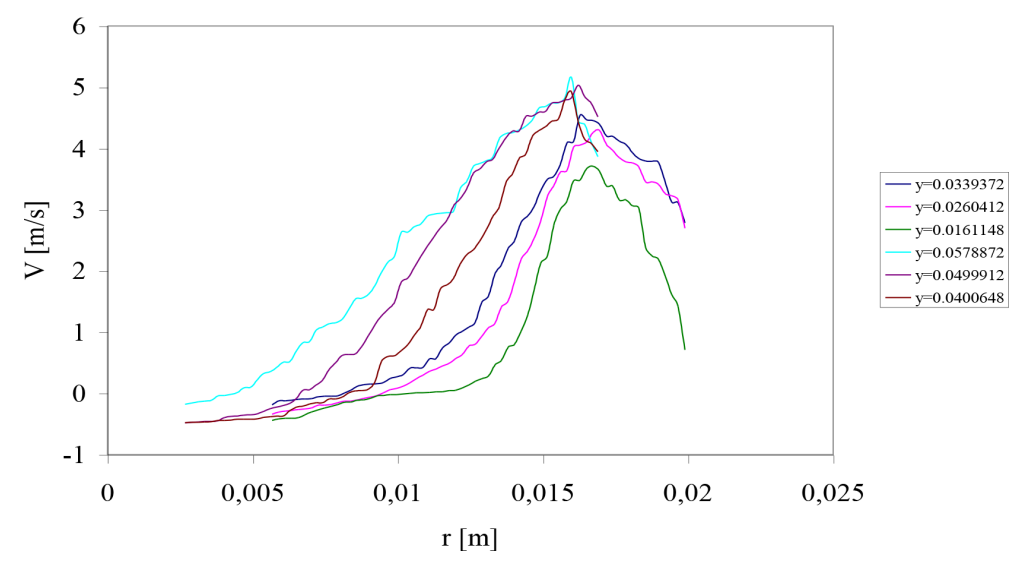

Figure 3: Radial profiles of $\mathrm{V}$ at different axial positions in the burner.

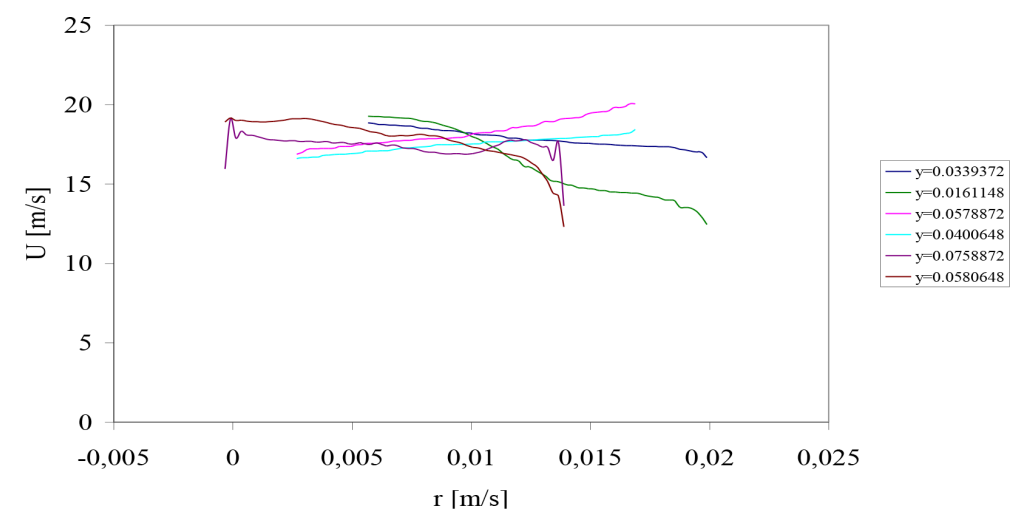

Figure 4: Radial profiles of $U$ at different axial position. 
shift of the maximum value of the velocity position outwardly of the jet, and finally a change in the slope.

The radial profile (V), for varying axial positions (y) defines the following areas: an increase in the radial velocity near to the reaction zone, due to the hot gases driving mechanisms that allow the reaction supply with oxidizer. Peak value of radial velocity is due to the coupling between volume expansion and thermophoresis. The mean radial velocity allows the evacuation of the burnt gases out of the reaction zone. Finally, a gradual decrease of the radial velocity (V) in the burned gas is observed (Fig. 3). The lag curve is due to the conical shape of flames.

In Fig. 4, for axial velocities (U) we observe however a change in velocity values. First increasing velocity is explained by the presence of the flame and by the mixing development which implies cold gas driving. The peak value of the radial velocity tends to be localized for all axial positions on the same axis for the first part and follow the flame front contour thereafter, which is absolutely conical. It is interesting to compare the values of these velocities according to different turbulence grids (Fig. 5). In fact, these are characteristics of both important driven zones and volume expansion.

Regarding the radial velocity $\mathrm{V}$, we note sensitivity to the turbulence. Indeed, we can see the trends are similar, the location of the peak velocity value shifts inward. It is interesting to compare the values of $U$ according turbulence grids. In fact, these characteristics are important drive zones and volume expansion. Clearly, the axial velocity $U$ is insensitive to turbulence variations (Fig. 6).

The visualization of the instant velocity fields obtained by PIV provides us information about the flow dynamic structure. It helps to obtain local information of the flow and consequently its dynamic structure (Figs 7 and 8). A good homogeneity of velocity in all areas is observed. As a result the potential core width remains constant and the large-scale perturbations on its periphery are absent. The velocity is almost constant in the potential core region until the reaction zone region after it decreases gradually. Negative velocity values are observed due to the existence of a recirculation zone. The radial velocity field is presented in Fig. 7.

In the same way as the axial velocity (Fig. 8), there are no perturbations from a dynamic point of view, only the chemical reaction effect is clear. In the potential core region, radial velocity intensities are small. Near the flame front region, particle acceleration is observed in

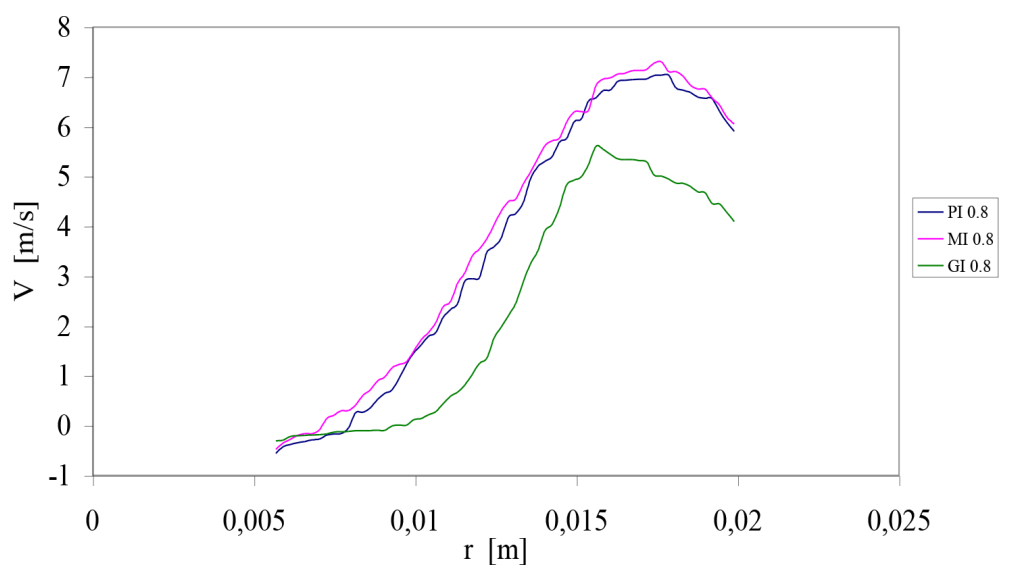

Figure 5: Radial profiles of $\mathrm{V}$ for different turbulence grids (P,M and $\mathrm{G})$. 


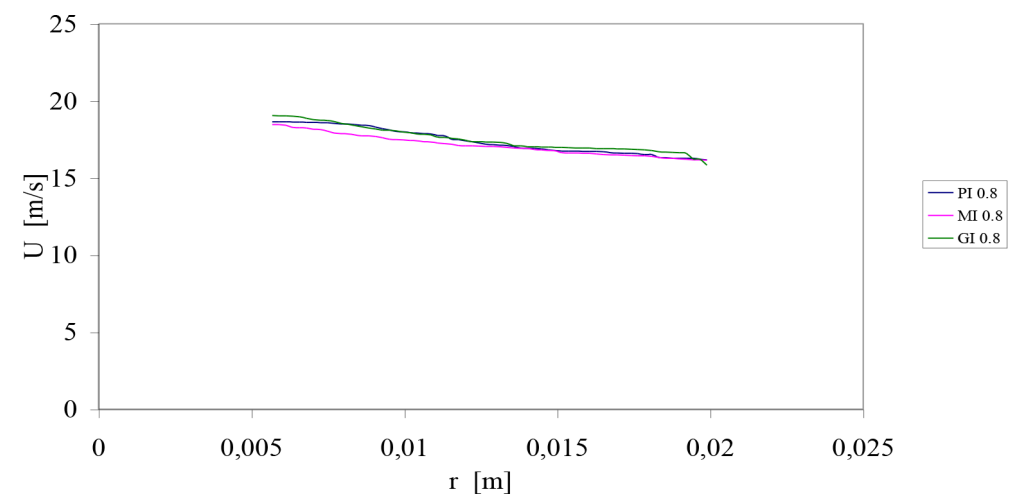

Figure 6: Axial velocity $\mathrm{U}$ as a function of the radius and for different turbulence grids (P, M and G).

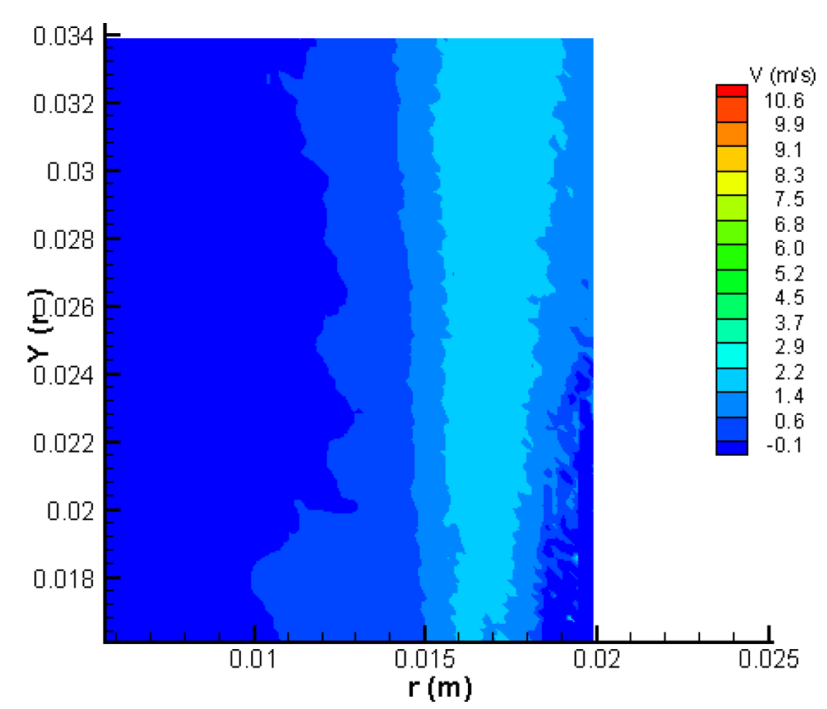

Figure 7: Radial velocity contours (V) for P grid and $\Phi=0,6$.

the opposite direction of the temperature gradient. First, there is a deceleration in particle movement before the flame front region. Passing this region, particles will be accelerated. When approaching the flame front region, the velocity vector deviation is clearly visible. It appears that a large laminarisation is generated by the flame in this region. This one prevents the development of large-scale instabilities and delays the mixture. The internal mixing layer presents a good lamination with little large-scale perturbations. In the outer layer, significant fluctuations and high velocity gradients are observed. This fact indicates the presence of less important turbulent mixing in the shear region while large structures are present outside.

On Fig. 9, we comparing the radial velocity $(V)$, for different equivalence ratio $(\Phi=0.6 \div$ 1.3). The results concern $G$ grid at axial distance $Y=0.0339 \mathrm{~m}$ from the burner exit. The results founded previously seem to be confirmed. Similar trends are observed where insignificant values in the potential core region are noted, followed by an increase of velocity in the mixing 


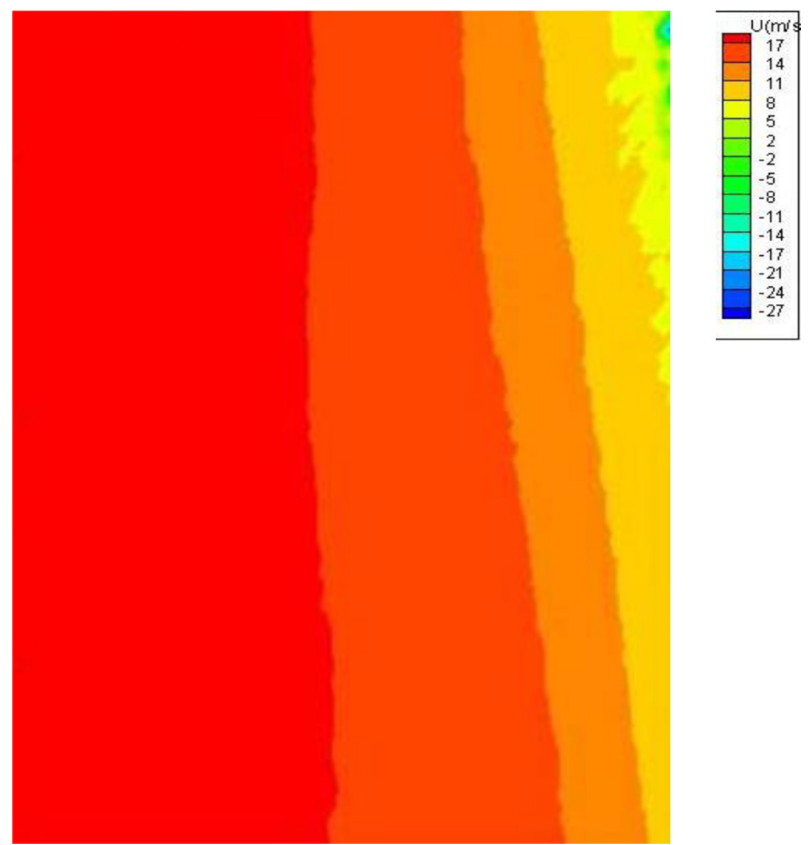

Figure 8: Axial velocity (U) contours for P grid and $\Phi=0,6$.

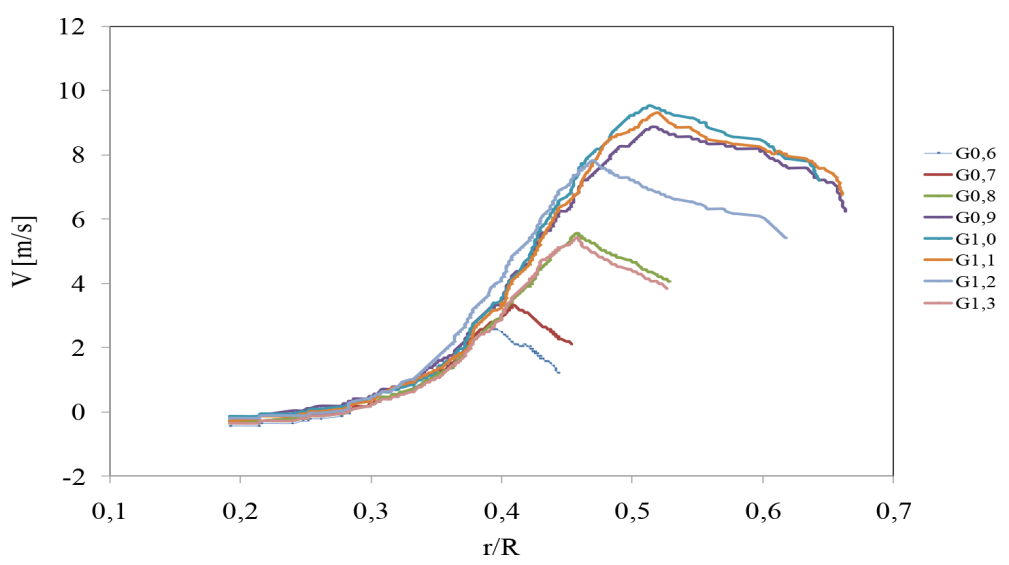

Figure 9: Radial velocity (V) profiles for different equivalence ratio.

region characterized by a maximum velocity in the flame front region, and finally a decrease in the burnt gases region (Fig. 9). Most important values of the radial velocity are corresponding well to the lean flames $(\Phi=0.6,0.7$ and 0.8$)$, followed by rich flames $(\Phi=1.3$ and 1.2$)$. The maximum values of the radial velocity are encountered in flames having the following stoichiometric ratios $(\Phi=0.9,1.0$ and 1.1). The results can be explained by the behavior of laminar flame speeds of methane as a function of equivalence ratio [26]. As observed before, the maximum values location of the radial velocity gives comparable flames positions around the 
stoichiometric ratios, and inward shifted values for rich and lean flames. Stoichiometric flames give uniform velocities, where the presence of an almost flat profile, indicates a rapid and uniform mixing between the different gases (short flame). The effect of equivalence ratio on the flame size was studied by Boulahlib et al. [2]. This one is in part controlled not only by the turbulence but also by the combustion.

The axial evolution of the mean axial velocity $U$ seems less influenced by the effects of equivalence ratio (Fig. 10). By focusing on the influence of equivalence ratio on the longitudinal velocity $U$, it appears the spatial shift is more specific to each equivalence ratio.

In the potential core region radial and axial velocity fluctuations are less important. The gradual increase of v' indicates the end of the potential core region. The region in the potential core is characterized by low and almost constant velocity fluctuations versus to velocity fluctuations in non-reactive case. These fluctuations decrease rapidly in the burned gas region after an increase across the flame front region where they reach their maximum values (Fig. 12). The evolutions of radial fluctuating velocities v', in the flames are

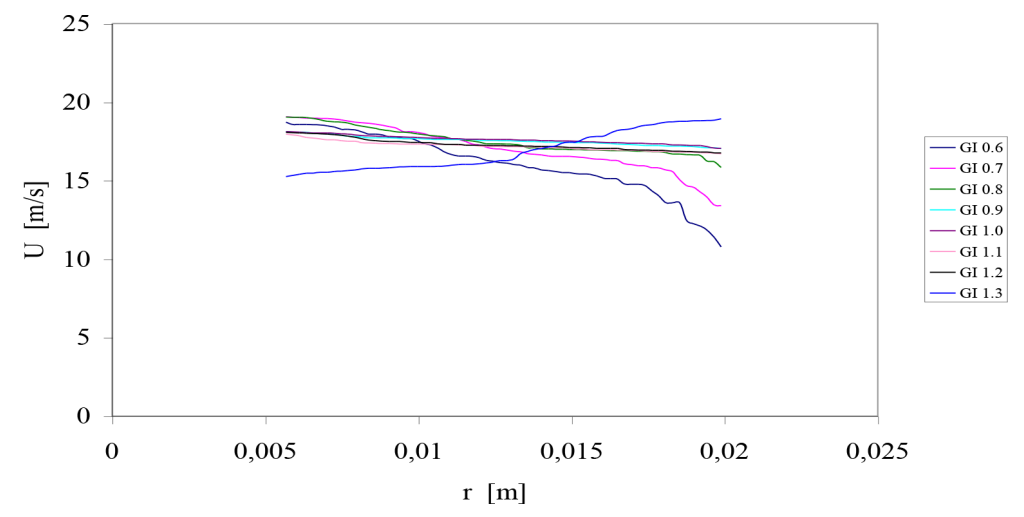

Figure 10: Axial velocity (U) depending on the burner radius, for different equivalence ratio.

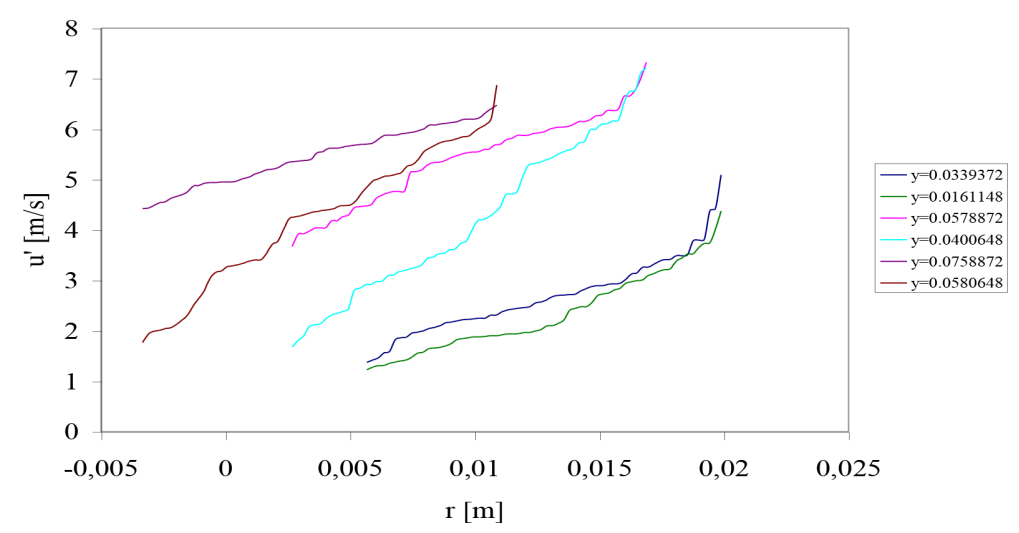

Figure 11: Radial profiles of axial velocity fluctuations u'(rms) at different axial positions in the burner. 


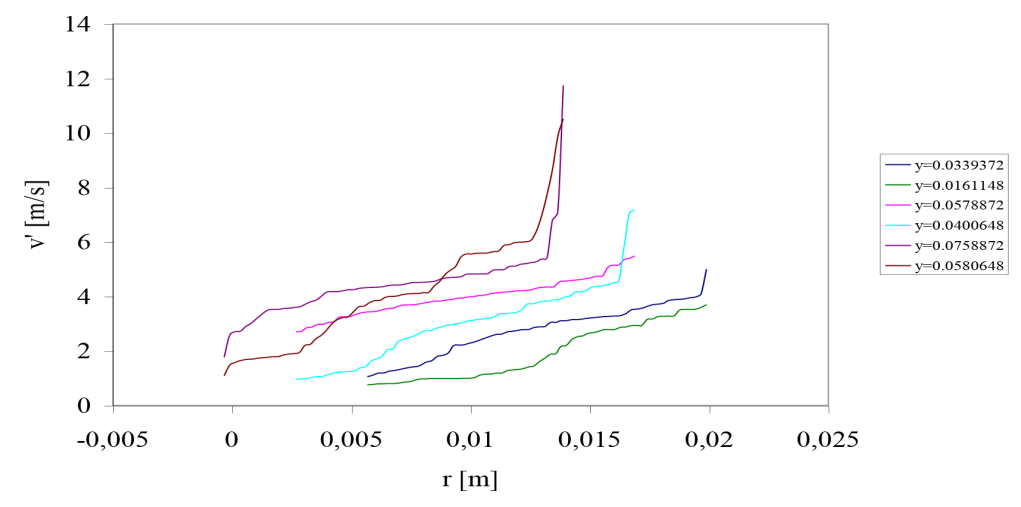

Figure 12: Radial profiles of radial velocity fluctuations v' (rms) at different axial positions.

almost identical to those already found to u' (Figs 11 and 12). Indeed at the radial and axial velocity fluctuations, we note low fluctuations in the potential core jet. The evolutions longitudinal fluctuating velocities in the flames are almost identical to that in the air jet except for some areas, where the slopes are different. Then begins a gradual increase in the u' value, corresponding to the output of the potential core.

The general trend, for lower heights at the end of the potential core is characterized by low and constant values comparable to those obtained in the non-reactive case. It peaked across the flame front, and finally decreases rapidly in the burned gas. The analysis of changes in values of the axial velocity fluctuations (u') indicates that they are roughly equal to the radial velocity fluctuations ( $\left.\mathrm{v}^{\prime}\right)$. The heights are not ordered because they refer to a couple of similar conditions.

\subsection{Isotropy (u'/v')}

The estimation of u'/v' ratio (Fig. 13), allows us to assess the turbulence isotropy generated in the flame by the grid. The u'/v' ratio, is important on the burner axis, and then remains almost constant with a value comprising between 1 and 2 near the reaction zone. The u' and v' remaining equals across the turbulent flame front thickness, then the isotropic character of turbulence will not be preserved before stabilizing finally. Thus, the flame tends to destroy the isotropic nature of turbulence. It is also well observed that the isotropy in lean flames is relatively well preserved. In fresh gas, the flame front being closest will influence the dynamic field. In addition, the v' increases as u' remains substantially constant. Behind the flame front, while v' begins to decrease, u' increases and u'/v' will have an important increase. In the region where there is mixing between burnt gases and the ambient air, v' increases again in the same proportions as u'. It is noted that the isotropic nature of turbulence in the flame is found to be disturbed across the flame front only.

\subsection{Turbulence intensity (u'/U) and kinetic energy (k)}

Equivalence ratio influences appreciably the evolution of turbulence intensity across the flame (Fig. 14). The mixing zone, in terms of turbulence intensity in the flame is being clear. Less important turbulence intensity is observed in the flames having an equivalence ratio 


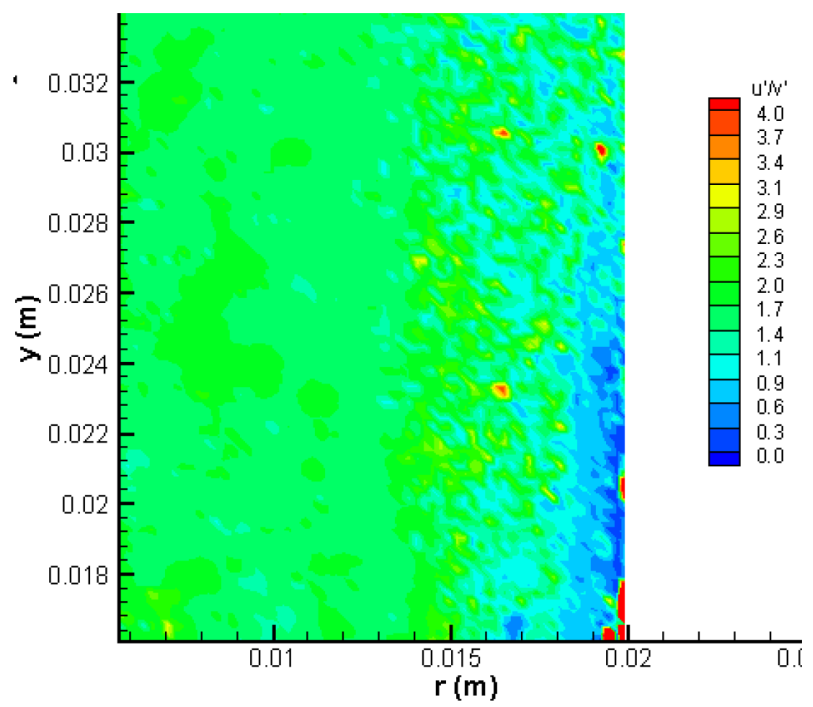

Figure 13: Isotropy contours in the flame: P grid and $\Phi=0,8$.

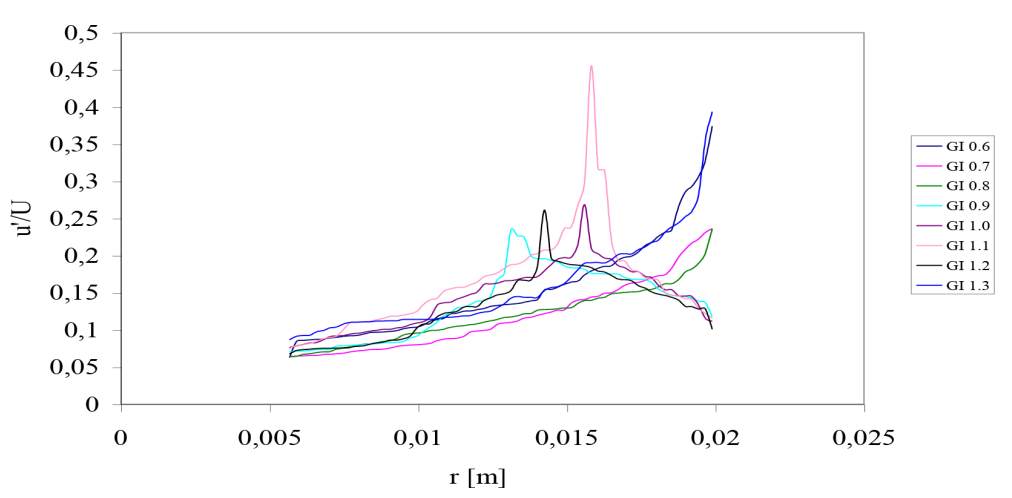

Figure 14: Turbulence intensity as a function of equivalence ratio.

$\Phi=0.7$ and 0.8 , followed by flames with $\Phi=0.6$ and 1.3 and finally $\Phi=1$. The turbulence intensity is maximum in the flame having an equivalence ratio $\Phi=1.1$, which corresponds well to the value of maximum heat release by the flame. A conclusion can be extracted is that, for lean or rich mixtures $u^{\prime} / \mathrm{U}$ is large. This likely reflects the fact that lean and rich flames are much longer in terms of size [2] and that away from the outlet of the burner, even without flame, the turbulence intensity continues to grow. Furthermore, for the lean flames $(\Phi=0.7$ and 0.8 ), regardless of their mean velocities, the $u^{\prime} / \mathrm{U}$ values are smaller than the turbulence intensity obtained in the jet. Therefore, the combustion reduces the turbulence intensity in the reactants for these flames.

The turbulence intensity $u^{\prime} / \mathrm{U}$ in the reactants, seems to remain constant until the mixing zone. From unburnt gases to products region, a gradual increase of turbulence intensity is observed. u'/U reaches the maximum value, which will be followed by a rapid decreasing 
across the flame front (Fig. 14). Nevertheless, the turbulence intensity for lean flames is attenuated by the flame. Initial turbulence intensity, defined by the grid geometry, does not modify the evolution of u'/U (Fig. 15). Thus, the turbulence intensity would tend to vary with the mixture equivalence ratio rather than its initial value at the burner exit.

In Fig. 16 and 17, it is apparent in the potential core region, low and constant values of the turbulence intensity are observed. At the potential core end, and further stream near the reaction zone, u'/U will increase. Outwardly, the maximum of $u^{\prime} / \mathrm{U}$ is located at the shear layer between the burnt and the ambient gases.

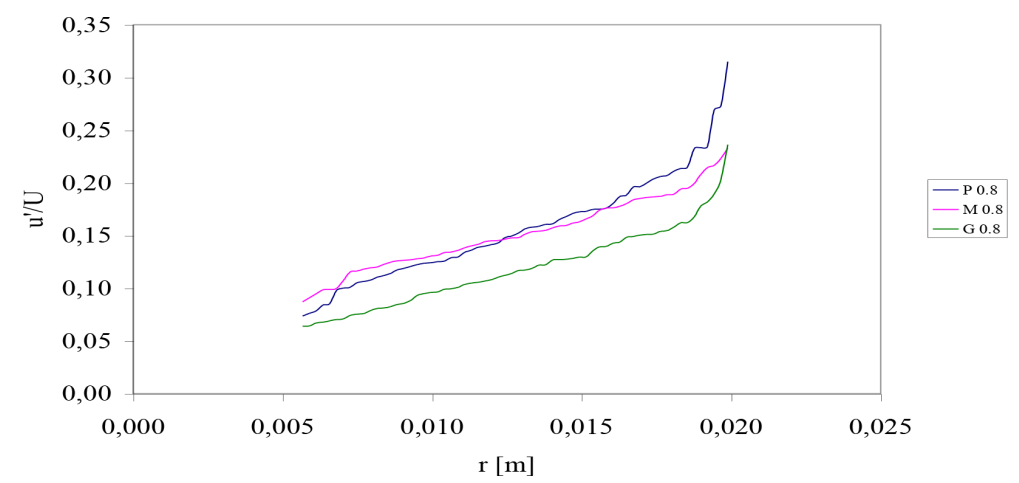

Figure 15: Turbulence intensity as a function of the burner radius and varying grid turbulence.

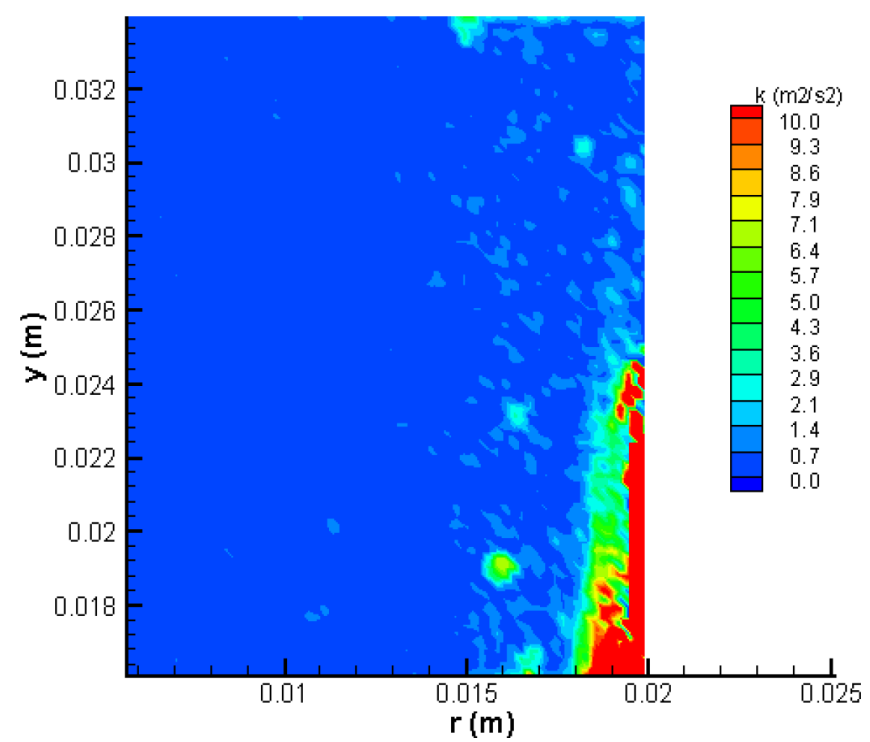

Figure 16: Turbulent kinetic energy k contours in the flame. 


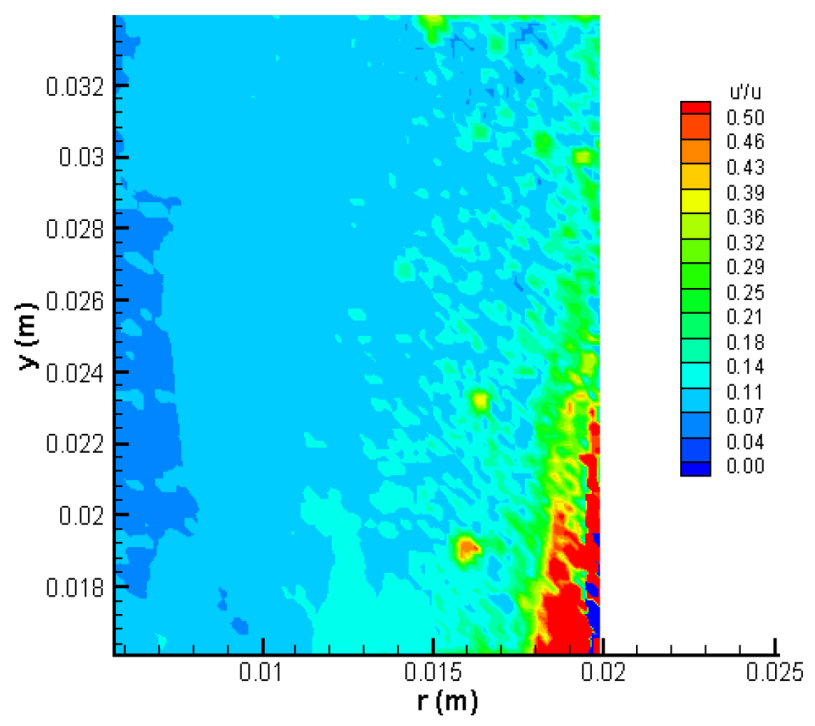

Figure 17: Turbulence intensity $\mathrm{u}^{\prime} / \mathrm{U}$ in the flame.

\section{ACKNOWLEDGMENTS}

The authors gratefully acknowledge technical support by the INSA/Coria laboratory in Rouen (France). The authors also thank A.M. BOUKHALFA (Coria Rouen) for the stimulating discussions, B. RENOU (Combustion Diagnostics Group Coria Rouen) for their help in setting up and operating the laser system.

\section{CONCLUSION}

The main objective of this study is to contribute to understand various complex phenomena of dynamic field that are involved in turbulent premixed methane-air flames. The different interactions between turbulence and combustion have been identified through a wide range of equivalence ratio and grid turbulence. The PIV technique was more appropriate and zirconium oxide was suitable for our study. It is shown that the grid used does not influence the radial velocity component $\mathrm{U}$ and $\mathrm{u}^{\prime} / \mathrm{U}$. The important velocity and turbulent kinetic energy values are obtained using the smallest ratio $(\mathrm{d} / \mathrm{M})$. The equivalence ratio appreciably influences the turbulence intensity evolution through the flame. The turbulence intensity would tend to vary with the mixture equivalence ratio rather than its initial value at the burner exit. The axial and radial velocity fluctuations ( $u$ ' and v') remaining equal across the turbulent flame front thickness, then the isotropic character of turbulence is not preserved. Thus, the flame tends to destroy the isotropic nature of turbulence. It is also well observed that the isotropy in lean flames is relatively well preserved.

LES: Large Eddy Simulation

\section{NOMENCLATURE}

DNS: Direct Numerical Simulation

PIV: Particle Image Velocimetry

PDF: Probability Density Function

LST: Laser Sheet Tomography 
Re: Reynolds number

$\mathrm{C}_{\mathrm{D}}$ : grid Pressure drop coefficient

u'/v' : isotropy

u'/U: turbulence intensity

$\mathrm{P}, \mathrm{M}$ and $\mathrm{G}$ : Grids

D: grid hole diameter

M: grid mesh

$\mathrm{U}$ : axial velocity

$\mathrm{V}$ : radial velocity

$\mathrm{k}$ : kinetic energy

u': velocity fluctuation in axial direction

v': velocity fluctuation in radial direction

$\mathrm{y}$ : vertical axis

r: horizontal axis

$\Phi$ : equivalence ratio

$\sigma$ : grid solidity

\section{REFERENCES}

[1] Glassman, I., Yetter, R.A. \& Glumac, N.G., Chapter 4 - Flame phenomena in premixed combustible gases. Combustion, 5th edn, Academic Press: Cambridge, pp. 147-254, 2015.

[2] Bray, K.N.C., Libby, P.A., Masuya, G. \& Moss, J.B., Turbulence production in premixed turbulent flames. Combustion Science and Technology, 25, pp. 127-140, 1981. http://dx.doi.org/10.1080/00102208108547512

[3] Boulahlib, M.S., Renou, B., Taupin, B., Boukhalfa, A. \& Nemouchi, Z., Experimental study of the influence of the equivalence ratio and turbulence on $\mathrm{CH} 4$-air premix flame in a Bunsen burner using Laser tomography. Sciences et Technologie, Série B, University Mentouri Constantine No. 22B, pp. 65-78, 2004.

[4] Boulahlib, M.S., Chekired, M. \& Boukebbab, S., Turbulence effect on lean premixed methane-air flame in a Bunsen burner. WIT Transactions on Ecology and the Environment, 186, pp. 719-725, 2014.

http://dx.doi.org/10.2495/ESUS140641

[5] Miles, P.C. \& Gouldin, F.C., Mean reaction rates and flamelet statistics for reaction rate modeling in premixed turbulent flames. Proceeding 24th Symposium on Combustion, The Combustion Institute, pp. 477-484, 1992.

[6] Bray, K.N.C., Champion, M. \& Libby, P.A., Mean reaction rates in premixed turbulent flames. Proceeding 22th Symposium (international) on Combustion, The Combustion Institute, pp. 763-769, 1988.

[7] Plessing, T., Kortschik, C., Peters, N., Mansour, M.S. \& Cheng, R.K., Measurements of the turbulent burning velocity and the structure of premixed flames on a low-swirl burner. Proceeding 28th Symposium on Combustion, Combustion Institute, pp. 359366, 2000. http://dx.doi.org/10.1016/s0082-0784(00)80231-3

[8] Deschamps, B., Etude spatiale et temporelle de la structure dynamique et scalaire des flammes turbulentes de premelange méthane-air, Ph.D thesis, Université d'Orléans, France, 1990. 
[9] Fragner, R., Halter, F., Mazellier, N., Chauveau, C. \& Gökalp, I., Investigation of pressure effects on the small scale wrinkling of turbulent premixed Bunsen flames. Proceedings of the Combustion Institute, 35(2), pp. 1527-1535, 2015.

http://dx.doi.org/10.1016/j.proci.2014.06.036

[10] Armstrong, N.W., Planar Flowfield Measurements in Premixed Turbulent Combustion, Cambridge University, 1992.

[11] Driscoll, J.F., Sutkus, D.J., Roberts, W.M.L., Post, M.E. \& Goss, L.P., The strain exerted by a vortex on a flame determined from velocity field images. Combustion Science and Technology, 96, pp. 213-229, 1994. http://dx.doi.org/10.1080/00102209408935356

[12] Frank, J.H., Lyons, K.M. \& Long, M.B., Measurement of conditional velocities in turbulent premixed flames by simultaneous OH PLIF and PIV. Combustion and Flame, 107, pp. 1-12, 1996. http://dx.doi.org/10.1016/0010-2180(95)00191-3

[13] Kalt, P.A.M. \& Bilger, R.W., Experimental investigation of turbulent scalar flux in premixed stagnation-type flames. Combustion and Flame, 129(4), pp. 401-415, 2002. http://dx.doi.org/10.1016/S0010-2180(02)00354-1

[14] Chen, Y.C. \& Bilger, R.W., Detailed measurements of local front structures in stagnation-type turbulent premixed flames. Proceeding of the Combustion Institute, 30, pp. 801-808, 2004. http://dx.doi.org/10.1016/j.proci.2004.08.162

[15] Chekired, M., Nemouchi, Z. \& Boulahlib, M.S., Numerical investigation of turbulent premixed methane/air jet flame using peters and williams reduced mechanism. International Journal of Fluid Mechanic Research, 41(1), pp. 31-50, 2014. http://dx.doi.org/10.1615/InterJFluidMechRes.v41.i1.30

[16] Battista, F., Troiani, G. \& Picano, F., Fractal scaling of turbulent premixed flame fronts: application to LES. International Journal of Heat and Fluid Flow, 51, pp. 78-87, 2015. http://dx.doi.org/10.1016/j.ijheatfluidflow.2014.08.006

[17] Tamadonfar, P. \& Gülder, Ö.L., Flame brush characteristics and burning velocities of premixed turbulent methane/air Bunsen flames. Combustion and Flame, 161(12), pp. 3154-3165, 2014.

http://dx.doi.org/10.1016/j.combustflame.2014.06.014

[18] Tamadonfar, P. \& Gülder, Ö.L., Effects of mixture composition and turbulence intensity on flame front structure and burning velocities of premixed turbulent hydrocarbon/air Bunsen flames. Combustion and Flame, 162(12), pp. 4417-4441, 2015. http://dx.doi.org/10.1016/j.combustflame.2015.08.009

[19] Tamadonfar, P. \& Guilder, Ö.L., Effect of burner diameter on the burning velocity of premixed turbulent flames stabilized on Bunsen-type burners. Experimental Thermal and Fluid Science, 73, pp. 42-48, 2016.

http://dx.doi.org/10.1016/j.expthermflusci.2015.09.006

[20] Levenţiu, C., Renou, B., Dănăilă, S. \& Isvoranu, D., Accurate measurements and analysis of the thermal structure of turbulent methane/air premixed flame. Energy Procedia, 85, pp. 329-338, 2016. http://dx.doi.org/10.1016/j.egypro.2015.12.259

[21] Maurice, G., Thiesset, F., Halter, F., Mazellier, N., Chauveau, C., Gökalp, I. \& Kourta, A., Scale analysis of the flame front in premixed combustion using proper 
orthogonal decomposition. Experimental Thermal and Fluid Science, 73, pp. 109$114,2016$.

http://dx.doi.org/10.1016/j.expthermflusci.2015.09.030

[22] Boyer, L., Laser tomograhic method for flame front movement studies. Combustion and Flame, 39, pp. 321-323, 1980.

http://dx.doi.org/10.1016/0010-2180(80)90028-0

[23] Bingham, D.C., Gouldin, F.C. \& Knaus, D.A., Crossed tomography laser-plane direct measurement of the surface flamelet normal. Proceeding 27th (International) Symposium on Combustion, The Combustion Institute, pp. 77-84, 1998. http://dx.doi.org/10.1016/s0082-0784(98)80392-5

[24] Zhang, Y., Chew, T.C. \& Bray, K.N.C., Displacement particle image velocimetry, lecture series, Von Karman Institute for Fluid Dynamics, Belgium, 1988.

[25] Borghi, R. \& Destriau, M., La combustion et la flamme, edn Technip Paris, pp. 47-48, 1995.

[26] Vagelopoulos, C.M., Egolfopoulos, F.N. \& Law, C.K., Further considerations on the determination of laminar flame speeds with the counterflow twin-flame technique. Twenty-Fifth Symposium (International) on Combustion, 25, pp. 1341-1347, 1994. http://dx.doi.org/10.1016/s0082-0784(06)80776-9 